\title{
Acontecimento enunciativo: 0 funcionamento semântico da designação constituída na e pela história
}

\author{
Rejane Fiepke Carpenedo (UFSM)* \\ https://orcid.org/0000-0001-7151-666X \\ Eliana Rosa Sturza (UFSM) ** \\ https://orcid.org/0000-0003-4085-0096
}

\section{Resumo:}

Este artigo se inscreve na Teoria da Enunciação, sob a perspectiva da Semântica do Acontecimento de Guimarães (2018), e toma o funcionamento semântico da Designação como fundamento para este estudo. A designação é a significação de um nome que funciona como elemento das relações sociais que ajuda a construir e das quais passa a fazer parte, constituindo-se sócio-historicamente. Para compreender este movimento de sentidos pela Designação nos propomos a analisar o sintagma nominal "Fora Temer" que passou a integrar a história da política recente do país e a repercutir nos mais distintos espaços. Nosso corpus se constitui de quatro sequências enunciativas, obtidas por meio de conteúdos compartilhados no Facebook e de sites de notícias, com o enunciado "Fora Temer" nos diferentes contextos sociais, e o movimento analítico da designação se dá com base no processo de reescrituração deste sintagma. A partir deste estudo, observamos que os diferentes modos de reescrituração da designação reforçam a expressão enquanto acontecimento enunciativo dotado de memória, bem como, se reescrevem os sentidos de reprovação, resistência e não aceitação, uma vez que a designação se constitui na e pela história.

Palavras-chave: Acontecimento Enunciativo. Designação. Enunciação. Reescrituração.

\section{Abstract: \\ Enunciative happening: the semantic functioning of the designation constituted in and by history}

This article is part of the Enunciation Theory, from the perspective of the Se-

* Doutoranda em Letras pelo Programa de Pós-Graduação em Letras, da Universidade Federal de Santa Maria (PPGL/UFSM). Bolsista CAPES. Mestra em Letras pelo PPGL/UFSM. Graduada em Jornalismo pela UFSM. E-mail: rejanefiepke@hotmail.com

** Professora Associada da Universidade Federal de Santa Maria. Coordenadora do Programa de Pós-graduação em Letras. Doutora em Linguística pela Universidade Estadual de Campinas. Mestra em Educação pela Universidade Federal de Santa Maria. Graduada em Letras pela Universidade Federal de Santa Maria. E-mail: listurza@gmail.com 
mantics of the Guimarães Event (2018), and takes the semantic functioning of the Designation as the basis for this study. The designation is the meaning of a name that functions as an element of social relations that helps to build and of which it becomes part, constituting socio-historically. In order to understand this movement of meanings by the Designation, we propose to analyze the noun phrase "Fora Temer" that has become part of the country's recent political history and has repercussions in the most different spaces. Our corpus consists of four images, obtained through Facebook and news sites, with the phrase "Fora Temer" in different social contexts, and the analytical movement of the designation takes place based on the rewriting process of this phrase. From this study, we observed that the different ways of rewriting the designation reinforce expression as an enunciative event endowed with memory, as well as, the meanings of disapproval, resistance and non-acceptance are rewritten, since the designation is constituted in and by history.

Keywords: Enunciative Event. Designation. Enunciation. Rewriting.

\section{Introdução}

Os sentidos estão sempre em movimento e conforme Guimarães (2002), cada enunciado é um acontecimento, instaurado em sua própria temporalidade. Assim, os acontecimentos históricos, sociais e políticos são também acontecimentos enunciativos, o que buscaremos compreender com este estudo por meio da análise do sintagma nominal "Fora Temer" enquanto designação constituída de historicidade e memória.

Tomando o cenário político recente como materialidade analítica deste estudo, é possível perceber que se teceu uma história cerceada de uma série de polêmicas que decorreram de uma grande insatisfação popular em relação ao modo como o ex-presidente, Michel Temer, assumiu a presidência do país. Conforme pesquisa realizada pelo Instituto Data Folha ${ }^{1}$, em setembro de 2017, o índice de aprovação do ex-presidente era de apenas 5\%, o maior índice de reprovação presidencial já constatado na história brasileira desde a redemocratização. Estes

1 http://g1.globo.com/jornal-nacional/noticia/2017/10/datafolha-reprovacao-temer-e -maior-desde-redemocratizacao.html fatos dialogam com a expressão que se alastrou pela nação, a forma nominal 'Fora Temer', que tomamos aqui, à luz da teoria da enunciação, na perspectiva da Semântica do Acontecimento, como uma designação: um nome significado na história.

0 início da crise política vivenciada no país teve seu ápice demarcado pelo processo de impeachment da presidenta Dilma Rousseff, do Partido dos Trabalhadores (PT). Dilma havia sido reeleita em 2014 e seu mandato se estenderia até 2018 , porém foi destituída de seu cargo em 31 de agosto de 2016 pelo Senado Federal. A partir desta data, a cadeira presidencial passou a ser ocupada pelo então vice-presidente Michel Temer, do Partido do Movimento Democrático Brasileiro (PMDB).

Diversos setores da sociedade discutiam e insinuavam a necessidade de instituir uma nova ordem econômica, política e jurídica, tomando como justificativa a falta de controle da crise que se instaurava no primeiro ano do segundo mandato de Dilma Roussef. Neste debate identificaram-se disputas simbólicas e conceituais que davam argumen- 
tos, a favor ou contra, para a instauração do processo de impeachment da presidenta, levando a duas interpretações entorno da legitimidade do ato, se resumindo na pergunta: “impeachment ou golpe?". Decorridos quatro anos deste acontecimento histórico e enunciativo, ainda não há qualquer indício de consenso popular acerca do fato.

De acordo com o Senado Federal (2016), na justificação para o pedido de impeachment, os juristas alegaram que a então presidente havia cometido crime de responsabilidade pela prática das chamadas "pedaladas fiscais" e pela edição de decretos de abertura de crédito sem a autorização do Congresso. 0 processo de impeachment de Dilma Rousseff iniciou em 2 de dezembro de 2015, no momento em que o ex-presidente da Câmara dos Deputados, Eduardo Cunha, deu prosseguimento ao pedido dos juristas Hélio Bicudo, Miguel Reale Júnior e Janaína Paschoal. Após a duração de 273 dias, o caso se encerrou em 31 de agosto de 2016, resultando na cassação do mandato, mas sem a perda dos direitos políticos de Dilma. A partir disso, o vice-presidente de Dilma assume a cadeira presidencial, e intrínseco a este acontecimento nasce a designação "Fora Temer" que em um curto espaço temporal abarca todas as esferas sociais.

Pretendemos, deste modo, que a análise da designação "Fora Temer" permita observar como a língua significa a história, e compreender como se dá o movimento de sentidos em cada gesto de reescritiração. Bem como, analisar o modo com os acontecimentos históricos, sociais e políticos são ao mesmo tempo acontecimentos enunciativos, uma vez que a história perpassa pela língua (Orlandi, 2002).

Para tal, após percorrer os caminhos teórico-metodológicos adotados para este estudo, mobilizamos um corpus constituí- do de imagens que apresentam esta designação, nas mais distintas condições, e como ela significa o político, enquanto conflito na língua e pela língua.

Para compreender a historicidade da designação "Fora Temer", também retomamos a outras designações ou expressões atribuídas a outros presidentes brasileiros que antecederam Michel Temer, no intuito de traçar o percurso da palavra 'Fora' enquanto significado de insatisfação manifesta aos governantes. Deste modo, é possível mobilizar os sentidos que a designação traz em si e entender como as palavras constituem seus sentidos por estarem afetadas pelas condições sócio históricas nas quais se formulam e circulam como "expressão" de desencanto, como neste caso de "Fora Temer".

Quando afirmamos que um enunciado produz significado na língua, compreendemos que na língua a palavra ou a forma nominal, na sua função semântica e na relação com a história, é o que faz o acontecimento enunciativo. Assim, uma mesma palavra pode ter sentidos diferentes e ser, a cada vez que aparece, um acontecimento enunciativo. Considerando esta perspectiva, apresentamos uma análise do sintagma nominal "Fora Temer" como um acontecimento enunciativo.

\section{Designação e acontecimento: uma perspectiva política}

A Semântica do Acontecimento, que é a base deste estudo, assegura que a análise do sentido da linguagem deve estar inserida no estudo da enunciação, no acontecimento do dizer. Dessa forma, se acredita que o sentido da palavra não se reduz a um conceito, e também não é fixo. 0 sentido se constitui em cada enunciado, sempre em relação ao acontecimento em que funciona. 
Sob a perspectiva da Semântica do Acontecimento, o acontecimento é descrito como "diferença na sua própria ordem" (Guimarães, 2002, p.12). E essa diferença na enunciação se dá a partir da temporalização: o acontecimento constitui uma temporalidade que não é cronológica, e sim simbólica. $\mathrm{O}$ acontecimento enunciativo está inscrito no interdiscurso, ou seja, na memória ideológica de sentidos, e assim instaura seu presente por meio da rememoração de um passado de enunciações, com o qual se projeta um futuro de possíveis interpretações. Daí a rememoração de dizeres que se reinscrevem como "Fora" e se atualizam a cada novo acontecimento tal como ocorre em "Fora Temer". Essa atualização que o acontecimento na sua temporalidade produz permite novos sentidos a cada enunciação, sentidos esses que estão condicionados pela história, pelas conjunturas sócio históricas e políticas que se explicitam e significam nas enunciações. Neste sentido, cada vez que se enuncia um "Fora Temer" novos sentidos vão alçando este sintagma nominal em uma designação.

Conforme Guimarães (2002, p.16), este movimento é político, e se caracteriza na enunciação "pela contradição de uma normatividade que estabelece (desigualmente) uma divisão do real e a afirmação de pertencimento dos que não estão incluídos". 0 que faz a enunciação um acontecimento é a não repetição dos sentidos, ao tomá-lo na temporalidade do dizer.

Guimarães (2005) afirma que para que se tenha um acontecimento é preciso destacar dois elementos que são imprescindíveis para sua realização: a língua e o sujeito na constituição histórica do sentido. Além destes elementos, considera-se também, como já mencionamos, a temporalidade dos acontecimentos, que é o fator relevante para definir o sentido das formas e expressões, produzindo novos gestos de leitura e novas interpretações. Ressaltando que para que tenhamos um funcionamento discursivo, é fundamental que haja uma materialidade histórica do real, um sujeito/enunciador que assume e produz as enunciações, bem como, um sujeito/enunciador que assume um lugar político, social e histórico do dizer e enuncia afetado pelo simbólico e num mundo vivido através do simbólico.

Assim, de acordo com Guimarães, o acontecimento instaura a sua própria temporalidade, e o sujeito do dizer não deve ser tomado como origem do tempo, mas pela temporalidade ao dizer. Deste modo, o próprio acontecimento é responsável pela temporalização, e não o sujeito.

A temporalidade é a representação de um presente que carrega em si uma latência de futuro, sem a qual não existe acontecimento de linguagem e nada é significado. A futuridade é essencial para a projeção e para que haja interpretação. 0 acontecimento só significa porque traz em si mesmo a projeção de um futuro. A partir desde presente e futuro, inerentes ao acontecimento, podemos afirmar que há um passado que permite que signifiquem, e que represente algo memorável. (Guimarães, 2018, p.43).

Apenas há sentido e significado próprios do acontecimento em virtude da latência de futuro, pois a enunciação recorta um passado como sendo memorável, um acontecimento histórico marcante, que neste estudo referese à situação política do país Brasil, fruto de inúmeros acontecimentos precedentes. Guimarães (2005, p.12) destaca que "o acontecimento é sempre uma nova temporalização, um novo espaço de conviviabilidade de tempos, sem a qual não há sentido, não há acontecimento de linguagem, não há enunciação".

0 acontecimento em questão é especificado pela designação e composto por um sintagma nominal: "Fora Temer". Esta expressão só existe e produz sentido em decorrência da história que traz e que a torna uma designação. Temer 
já existia, mas "Fora Temer" não é Temer, pois se constitui como designação em discursos em um tempo-espaço determinados, configurando-se em discursos midiáticos, em redes sociais, em falas de manifestações, constituindo-se de sentidos que carregam argumentos de toda ordem em relação ao estado das coisas, às situações políticas que emergem a partir do momento em que Temer se tornou o presidente. "Fora Temer" significa o desejo de retirá-lo deste lugar da presidência, por entender que não é legítimo o modo pelo qual ele assumiu este posto. Guimarães (2005) comenta que

A designação é o que considero a significação de um nome enquanto sua relação com outros nomes e com o mundo recortado historicamente pelo nome. A designação não é algo abstrato, mas linguístico e histórico. Ou seja, é uma relação linguística (simbólica) remetida ao real, exposta ao real. (GUIMARÃES, p. 54).

Assim, compreendemos que a designação, enquanto representação de uma temporalidade e constituída de historicidade, produz sentidos a partir das condições sócio -históricas e políticas em que se situa, levando em consideração o passado e projetando futuridade. "Fora Temer" não se configura em uma expressão isolada, mas enquanto remetida ao real carrega em si o recorte de um fato histórico, pois conforme Guimarães (2005) "um nome, ao designar, funciona como elemento das relações sociais que ajuda a construir e das quais passa a fazer parte". Portanto, "Fora Temer" é designação na medida que traz sempre a memória o fato histórico e o atualiza, novos sentidos emergem porque a língua muda por uma temporalidade que constrói o "Fora Temer" como um acontecimento enunciativo.

Para compreender como um sintagma nominal é tomado enquanto designação, é preciso considerá-lo no funcionamento enunciativo da língua. Na perspectiva da
Semântica do Acontecimento, a designação é alçar um nome a um construto, ou seja, é analisar seu funcionamento na temporalidade do acontecimento. Um sintagma como "Fora Temer" se singulariza como designação à medida que passa a significar a história (relembrada pelo nome próprio Temer, que o situa no tempo histórico) e a conjuntura política na qual se institui como a expressão de um descontentamento até a uma reprovação. 0 que também expande a potência de sentidos a serem atribuídos a cada funcionamento desta designação é como ela reaparece em outros contextos (como as imagens a seguir vão evidenciar) e ressurge em novas enunciações.

Com o pressuposto de que "a palavra faz a história" (Guimarães 2005), realizamos uma pesquisa paralela quanto à palavra Fora relacionada aos dizeres de descontentamento que circularam em relação aos demais ex -presidentes do país. Constatamos que a palavra "Fora" tem configurando designações relativas a diversas figuras presidenciais ao longo da história do país, sendo a primeira ocorrência registrada em uma manifestação público-partidária, sob os gritos e dizeres escritos de "Cai Fora Figueiredo".

Os presidentes José Sarney, Fernando Henrique Cardoso e Lula $^{3}$ também foram designados por "fora", mas de modo mais restrito e sem muita repercussão midiática, justamente porque aconteceram em conjunturas políticas diferentes, sobretudo por um grau de descontentamento menor, tendo relação com um índice inferior de reprovação desses presidentes. No entanto, em 1992, a designação ganhou relevância e circulou nas manifestações contrárias ao governo de

\footnotetext{
2 http://www.memorialdademocracia.com.br/ publico/thumb/4721/740/440

3 http://g1.globo.com/Noticias/Politica/0 „MUL82958-5601,00 LULA+E+ALVO+DE+PROTESTOS+EM+CAPITAIS.html
} 
Collor, pois, sob as cores verde e amarelo, os semblantes esbravejavam "Fora Collor", conclamando pela instauração de um processo de impeachment, que acabou por acontecer. Vale ressaltar que todos os acontecimentos enunciativos designados por "Fora presidente" circularam especialmente em grandes atos e manifestos públicos e o uso das cores da bandeira brasileira atribuía a essa designação na época um significado nacionalista, em certa medida convergiam nesta designação o desejo de uma nação.

0 "Fora presidente" transformou a designação em uma palavra de ordem para pressionar o congresso nacional a votar a favor da saída do presidente. 0 funcionamento semântico de "Fora Temer" e "Fora presidente" parece convergir a uma identidade semântica, à medida que a primeira reescritura o já dito do segundo e ambos significam descontentamento, reprovação.

\section{Designação "Fora Temer": movimento de sentidos pela reescrituração}

0 corpus mobilizado para esta análise é constituído por quatro imagens que apresentam a designação "Fora Temer" em distintos espaços, que circulavam nas redes sociais. Tais imagens de livre circulação em redes sociais são reescrituras de "Fora Temer", constituídas em discursos que manifestavam um desagravo à figura do ex-presidente da república. Os argumentos do discurso político de descontentamento, neste caso, se reescrevem pela designação "Fora Temer", nas diferentes imagens. Conforme Guimarães (2018)

A reescrituração é o modo de relação pelo qual a enunciação rediz o que já foi dito. Há reescrituração quando um elemento $\mathrm{Y}$ de um texto (uma palavra, uma expressão, por exemplo) retoma um outro elemento $\mathrm{X}$ do texto. Neste caso Y reescritura X. Este modo de relação enunciativa leva a interpretar uma forma como diferente de si. 0 elemento que reescritura atribui (predica) sentido ao reescriturado. Uma característica fundamental da reescrituração é que ela não se caracteriza pelas relações segmentais, ou de contiguidade, própria dos modos de articulação. [...] Consideramos que a reescrituração pode ser por repetição, substituição, elipse, expansão e condensação. (GUIMARÃES, 2018, p.87)

Cada imagem do corpus é o registro do acontecimento enunciativo e, portanto, a designação "Fora Temer" significa também pelo que cada imagem possibilita o leitor ler e interpretar. Tais imagens evidenciam, neste sentido, a historicidade e memória da qual se constituem a designação analisada, e as mobilizamos como Sequências Enunciativas no movimento analítico.

\section{Sequência Enunciativa 1 (SE1):}

A primeira SE selecionada é oriunda da Fanpage do Facebook intitulada "Mais Geografia", publicada no dia 07 de setembro de 2017, data em que se comemora a Independência do Brasil. A SE1 ressignifica a reprodução de um quadro de Pedro Américo, que registra um momento histórico do Brasil, conhecido como o Grito do Ipiranga, no qual se celebra a Independência do Brasil de Portugal. Esta nova apresentação da imagem se transforma em um novo acontecimento enunciativo ao reescriturar o sintagma nominal "Independência ou Morte" por "Fora Temer", em um procedimento semântico de substituição.

A reescrituação, segundo Guimarães (2002) é um procedimento de redizer, mas nunca de modo igual, pois cada redizer é acontecimento enunciativo, constituído por uma temporalidade. As reescrituras, que podem ser apresentadas no plano linguístico em novas formas nominais, já não signi- 
ficam o mesmo, pois a cada vez que aparecem essas formas (designações, nomeações, nomes), sentidos outros se constituem no dizer, sobretudo porque o espaço do acontecimento se dá em outra condição histórica, social e política.

O homem à frente do grupo, que simbolicamente remete a Dom Pedro I, levanta uma de suas mãos empunhando uma espada e brada "Fora Temer". Ao trazer a memória deste fato histórico e atualizá-lo para contexto político atual, identificamos uma relação semântica, permitida pela reescrituração, produzindo-se assim uma enunciação do já dito, porém, a temporalidade da enunciação possibilita um novo sentido, que se coloca neste caso pelo efeito de ironia que a imagem produz. 0 presidente está significado pela designação "Fora Temer", e esta se configura em um desejo de retirá-lo do poder. Livrar-se deste presidente se assemelha ao que significou o Brasil ter se tornado independente de Portugal, ainda que a conjuntura política recente traga para esta imagem novos sentidos como o de retirar do poder um presidente que não é aprovado porque não se reconhece a legitimidade do ato que o levou à presidência do país.

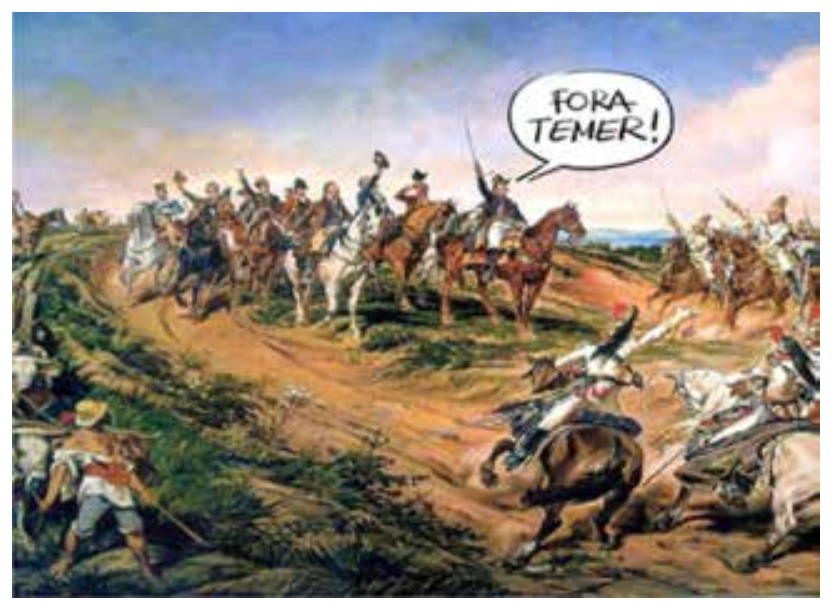

Tela "Independência ou Morte" também conhecida como "O Grito do Ipiranga" do pintor brasileiro Pedro Américo ${ }^{4}$.

4 Disponível na Fanpage Mais Geografia, pelo link: https://www.facebook.com/muitomaisgeogra-
Guimarães (2002, p.12) afirma que o "acontecimento enunciativo configura o seu presente pela rememoração de um passado de enunciações (os memoráveis), a partir dos quais projeta um futuro de interpretação". Com isso, percebemos que a SE1 1 traz a rememoração de uma data histórica e por meio da designação "Fora Temer" ressignifica o acontecimento, instaurando a sua própria temporalidade, e produzindo sentidos em decorrência da sua inscrição no interdiscurso.

Neste acontecimento enunciativo, "Fora Temer" equivale à "Independência ou Morte" no século XIX, num desejo de liberdade para a nação, e fim da submissão à metrópole portuguesa. No século XXI, no contexto político e social atual, ressignificando a rememoração histórica, "Fora Temer" equivale a libertar-se de um governo que não agrada ao povo, mostrando rejeição à figura presidencial. Os sentidos consistem basicamente em cortar os laços, e tirar o presidente do seu lugar.

\section{Sequência Enunciativa 2 (SE2):}

A SE2 é uma fotografia e pertence a uma matéria jornalística da Revista Fórum. 0 texto "indígenas trouxeram a frase 'Fora Temer' pintada no corpo durante uma cerimônia tradicional", que acompanha a foto mostra a extensão que a designação toma dentro de um discurso de descontentamento o qual inclui todos os pertencentes a nação. A especificação que a designação apresenta ao estar inscrita e escrita nas costas de um índio, permite inferir o alcance que o sentido de descontentamento, rejeição, reprovação ao presidente toma nas diferentes textualidades. 0 acontecimento enunciativo se materializa na escrita "Fora Temer" no

fia/photos/a.612109278933183.1073741827 $.612098042267640 / 1217765761700862 /$ ty pe $=3 \&$ theater 
corpo do indígena. Nesta reescritura a especificação se dá por conta da sua circulação e sua formulação em um espaço real que se significa no espaço de enunciação. Estes sujeitos índios se colocam como sujeitos políticos da enunciação e resignificam o descontentamento na sua especificidade, os inclui no conjunto dos que reprovam o presidente.

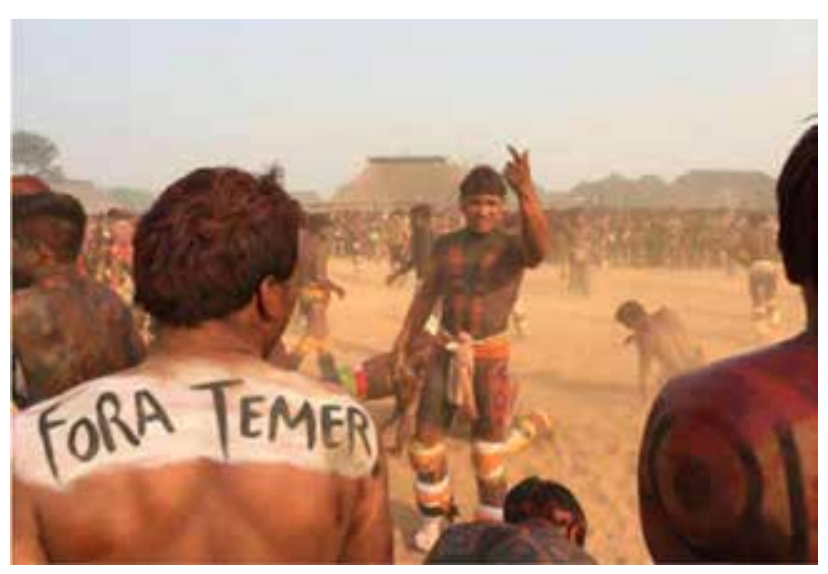

Imagem Disponível na matéria jornalística da Revista Forum $^{5}$

Esperam-se posicionamentos de ordem política em ambientes como manifestações, espaços públicos e geralmente em eventos agendados para tal fim. Desse modo, torna-se inesperado o protesto inscrito em um espaço tão oposto, e um contexto sócio-histórico que por tradição não é reconhecido, sobretudo, pela mídia como sujeitos políticos. Eles aqui disputam um espaço do dizer para significar sua posição frente aos fatos atuais do país, neste caso, significar sua reprovação ao presidente Temer.

De acordo com Guimarães (2002)

Os espaços de enunciação são espaços de funcionamento de línguas, que se dividem, redividem, se misturam, desfazem, transformam por uma disputa incessante. São espaços "habitados" por falantes, ou seja, por sujeitos divididos por seus direitos ao dizer e aos modos de dizer. (GUIMARÃES, 2002, p. 18).

5 Link:https: / / www.revistaforum.com. br/2016/08/15/povos-indigenas-do-xingu-fazem-protesto-contra-temer-em-ritual/
Assim, temos a especificação pelo espaço de enunciação, que são as costas de um índio. Este espaço, tomado pelo acontecimento enunciativo tem sentidos de desprezo e reprovação pelo presidente, demonstrando a sua não-aceitação pelo povo indígena.

Na SE2 há efeitos de sentido decorrentes da observação de dois espaços marcantes: o espaço físico, aldeia indígena; e o espaço simbólico como produção de sentido, que são as costas do índio. Em um momento tradicional da cultura, na prática de rituais, a designação "Fora Temer" reforça os sentidos de rejeição.

\section{Sequência Enunciativa 3 (SE3):}

A SE3 também é uma fotografia em um contexto que se tornou notícia, no site Brasil 247, por ser inusitada. Em um muro de um cemitério alguém escreveu "Entra Temer".

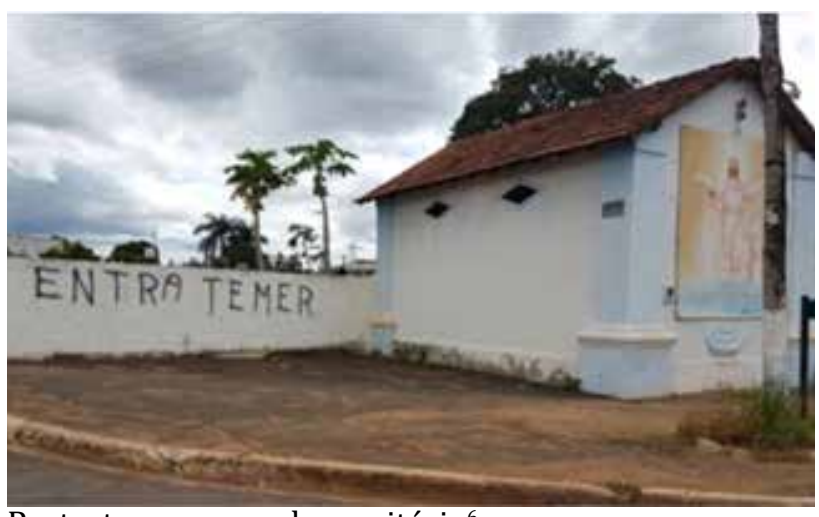

Protesto em muro de cemitério ${ }^{6}$.

Essa designação apresenta-se em uma forma nominal que se opõe à designação "Fora Temer" na sua reescrituração por um procedimento semântico de antonímia do 'fora', pois quando todos proferem "Fora Temer", ela diz "Entra Temer". Mesmo em um movimento contrário, mantém os mesmos sentidos, reforçando-os à medida que remete aos de reprovação em relação ao presidente, talvez por um extremo da expressão.

6 Disponível no link: https://www.brasil247.com/ pt/247/brasil/292882/Em-protesto-inusitado-funcion \%C3\%A1rio-de-cemit\%C3\%A9rio -escreve-'entra-Temer'.htm 
Considerando a inscrição da designação em um muro de cemitério, a reprovação se equivale ao desejo de morte do presidente. Embora pareça uma ironia, a designação por antonímia é o ápice da reprovação, a posição do sujeito e a relação com a história seguem iguais.

A posição enunciativa permanece a mesma, pois a posição social e política do enunciador continua sendo de reprovação e resistência. Desse modo, há um jogo de linguagem, em que o uso de um termo oposto mantém os sentidos de reprovação como objeto. 0 enunciador diz de modo diferente, mas diz o mesmo, mantendo uma identidade semântica mesmo que na aparência as designações se apresentem em formas nominais opostas. É a relação com a história que possibilita que a língua no seu funcionamento signifique essas duas designações como relativas a não aceitação de Temer como presidente.

\section{Sequência Enunciativa 4 (SE4):}

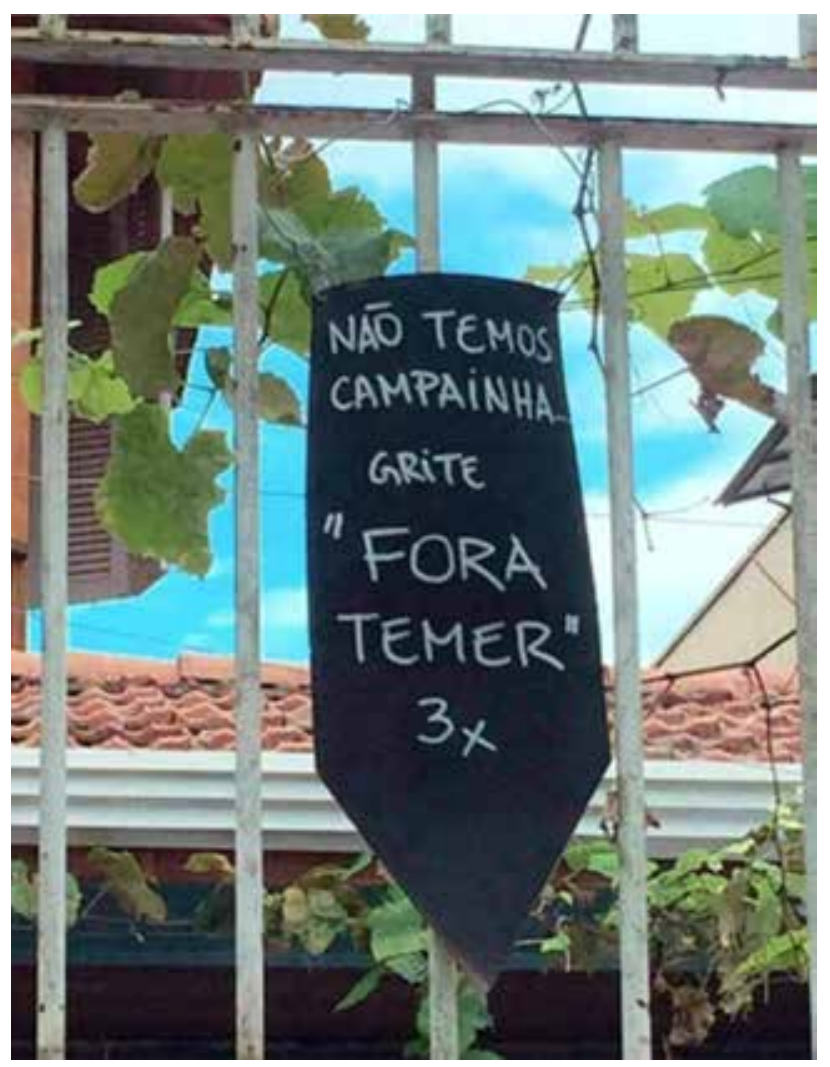

Divulgação em blog pessoal de ativismo político
A SE47 é uma imagem que circulou em redes sociais que indica uma reescritura da designação em outro tempo e espaço no qual o acontecimento enunciativo mostra que a designação "Fora Temer" se desloca do seu lugar imediato e comum de circulação e de veiculação enquanto um dizer de manifestação de descontentamento político em relação ao presidente atual.

Neste caso tem-se a designação reescriturada em um enunciado que a mobiliza pelo modo de expansão e no sentido de generalização do que é manifestação e reprovação, ou seja, enfatiza o ato de dar voz e de se fazer ouvir. Esta forma de apresentação da designação "Fora Temer", em uma relação de articulação com enunciado anterior, para justificar que é necessário gritar, significa se fazer ouvir de modo muito específico, no intuito de identificar-se pelo manifesto da reprovação, da rejeição. A designação "Fora Temer" significa em uma relação de sinonímia descontentamento, reprovação, rejeição.

Na SE4 há um segundo sentido em movimento, de acordo com os sentidos da reescrituração postulados por Guimarães (2018, p.93), que é o de especificação. Além de sugerir que o interlocutor grite a designação "Fora Temer" para fazer-se ouvir, especifica de que forma este ato deve ser feito: "três vezes". Isto movimenta sentidos de reafirmação de todos os sentidos que a designação já trás em si, constituídos pela memória e historicidade.

As sequências enunciativas analisadas permitem observar que todo acontecimento histórico-social é também um acontecimento enunciativo, pois de alguma forma é perpassado e marcado pela manifestação

7 Disponível em: https://www.facebook.com/ search $/$ top $/$ ? q=grite $\% 20$ fora $\% 20$ temer $\% 20$ 3x\&epa=SEARCH_BOX 
da língua, que neste caso foi o surgimento de uma designação específica decorrente de uma situação política particular que se inscreveu na história.

\section{Considerações finais}

Este estudo se debruçou sobre uma análise da designação "Fora Temer" no intuito de compreender o seu funcionamento semântico como acontecimento enunciativo em sua relação com a história. Designar é dar uma especificidade para algo que já existe, assim, sabe-se que Temer existe, mas "Fora Temer" não é Temer, é uma manifestação de rejeição à figura política que o sujeito representava e pelo lugar que ora ocupava. A designação "Fora Temer" aparece em todas as sequências enunciativas reescrituradas, ainda que se redizendo a cada vez que se apresenta nestas textualidades das SE's, o sentido nunca se repete. Cada vez que aparece é um acontecimento enunciativo, mostrando como a língua significa a história.

Sabendo que a história é constitutiva da língua, o "Fora Temer" como designação apresenta-se na historicidade pelo modo como se constitui particularmente em cada sequência enunciativa. A história está inserida nessa designação. "Fora Temer" não existia antes de Temer ter chegado ao poder pelo processo de Impeachment. Deste modo, existe um acontecimento na história, em que tudo que vem antes desse momento histórico é um Temer vice-presidente de pouca visibilidade, e tudo que ocorre posteriormente é marcado pela designação "Fora Temer".

Assim, a análise da designação nos seus mais diversos movimentos, a partir do processo analítico da reescrituração, equivale a uma análise histórica, uma vez que o acontecimento enunciativo implica historicidade. "Fora Temer" é uma posição ideológica e também uma conjuntura alinhada de reprovação, como demonstram as pesquisas.

A partir deste estudo, observamos que as diferentes ocorrências das designações e o modo como elas se reescrevem em cada textualidade das sequências enunciativas, há um acontecimento enunciativo que mantém os sentidos de reprovação, resistência e não aceitação, ainda que nem sempre do mesmo modo, dado que cada vez que aparece a designação "Fora Temer" a conjuntura política e histórica já não será a mesma. 0 movimento de reescrituração como ferramenta analítica possibilitou observar como em cada acontecimento enunciativo há sentidos que permanecem, ao mesmo tempo em que novos sentidos se instauram.

\section{Referências}

GUIMARÃES, Eduardo. Semântica do acontecimento: um estudo enunciativo da designação. Campinas, SP: Pontes, 2a edição, 2005.

Designação e espaço de enunciação: um encontro político no cotidiano. Letras $\mathrm{n} \mathbf{0} 26$, Língua e Literaturas: Limites e Fronteiras.

Espaço de enunciação, cena enunciativa, designação. Laboratório Corpus: UFSM, Jan./mar 2014.

Semântica do Acontecimento. Campinas: Pontes Editora, 2002.

Semântica: enunciação e sentido. Campinas, SP: Pontes Editora, 2018.

MEMORIAL DA DEMOCRACIA. Cai fora, Figueiredo. Disponível em: http://www. memorialdademocracia.com.br/publico/thumb/4721/740/440. Acesso em: $15 / 10 / 2019$.

ORLANDI, Eni. Análise de Discurso: princípios e procedimentos. $4^{\underline{a}}$ ed. Campinas: Pontes, 2006.

PAYER, Maria Onice. Memória da língua: imigração e nacionalidade. São Paulo: Escuta, 2006.

SENADO FEDERAL. Impeachment de Dilma 
Rousseff marca ano de 2016 no Congresso impeachment-de-dilma-rousseff-marca-anoe no Brasil. Disponível em: https://www12. de-2016-no-congresso-e-no-brasil. Acesso em: senado.leg.br/noticias/materias/2016/12/28/ 14 maio 2020.

Recebido em: $15 / 05 / 2020$ Aceito em: 18/02/2020

Esta obra está licenciada com uma Licença Creative Commons Atribuição 4.0 Internacional. 